\title{
Planned home deliveries in Finland, 1996-2013
}

\author{
Katja Ovaskainen $\mathbb{1}^{1,2} \cdot$ Riitta Ojala $^{1} \cdot$ Kati Tihtonen $^{3} \cdot$ Mika Gissler $^{4,5} \cdot$ Tiina Luukkaala $^{6,7} \cdot$ Outi Tammela $^{1}$
}

Received: 2 July 2018 / Revised: 7 October 2018 / Accepted: 24 October 2018 / Published online: 13 November 2018

(c) Springer Nature America, Inc. 2018

\begin{abstract}
Objective To evaluate trends and perinatal outcomes of planned home deliveries in Finland.

Study design All infants born in 1996-2013, excluding those born preterm, by operative delivery, and without information on birth mode or gestational age, were studied. The study group included 170 infants born at home as planned, 720,047 infants born at hospital were controls.

Result The rate of planned home deliveries increased from 8.3 to 39.4 per 100,000. In the study group 63\%, containing two perinatal deaths, were not low-risk pregnancies according to national guidelines. The rate of hypothermia, asphyxia, and need of invasive ventilation was increased in low-risk home deliveries. One infant had a major congenital malformation. Maternal outcomes were favorable.

Conclusion The rate of planned home deliveries increased. Guidelines for low-risk deliveries were not followed in a majority of cases, including two perinatal deaths. Even in low-risk home deliveries, the neonatal morbidity appeared to be increased.
\end{abstract}

\section{Introduction}

In many studies perinatal and neonatal mortality rates are higher among planned home deliveries than among hospital deliveries [1-5], although there are also reports showing no difference between them [6-14]. Data on neonatal outcome and morbidity are also controversial. Infants born at home are admitted less often to neonatal intensive care units than those born in the hospital $[1,15,16]$, but there are two studies showing more admissions[17, 18].

\section{Katja Ovaskainen}

katja.ovaskainen@pshp.fi

1 Department of Neonatology, Tampere University Hospital, Tampere, Finland

2 School of Medicine Doctoral Programme, University of Tampere, Tampere, Finland

3 Department of Obstetrics and Gynecology, Tampere University Hospital, Tampere, Finland

4 National Institute for Health and Welfare, Helsinki, Finland

5 Nordic School of Public Health, Gothenburg, Sweden

6 Tampere University Hospital, Research, Development and Innovation Center, Tampere, Finland

7 Tampere University, Health Sciences, Faculty of Social Sciences, Tampere, Finland
Mothers who deliver at home as planned are more often older $[2-4,9,12,14,15,19-21]$, non-smokers[6, 12, 21], married [15, 17, 21], and have had more earlier pregnancies $[14,19]$ and deliveries $[3,4,9,10,15,17,19,20]$, and the length of pregnancy is more often almost or more than 42 weeks $[2,3,7,9-12,14,15,20]$. Socioeconomic status and/or education are usually better among these women $[4,7,12,15,21]$. Intrapartum interventions and adverse maternal outcomes occur less often in planned home deliveries [6, 15].

Comparison of the mortality and morbidity results between different countries on different regions is difficult, but could be improved by taking account the variation in governmental support and regional integration of planned home births to the health care system. The settings of the previous studies as also patient selection and health care facilities [3] of the studies have been variable. In some studies, strict selection criteria have been used for women planning home delivery with trained certified midwives highly integrated to the public health care system $[7,10]$.

Unexpected complications cannot be ruled out even in so-called low-risk pregnancies [22]. In spite of this, even some mothers with risky pregnancies have had planned home deliveries [23]. Transfer to the hospital during or after labor is needed in $8-32 \%$ of home deliveries, usually before the birth $[24,25]$. 
The primary purpose of this study was to establish perinatal and maternal mortality and morbidity data in planned home deliveries compared with in-hospital deliveries. We also wanted to establish prevalence rates and trends in connection with planned home deliveries in Finland.

\section{Methods}

The data were collected from the Medical Birth Register and the Register of Congenital Malformations maintained by the National Institute for Health and Welfare. The Medical Birth Register contains data related to all live births and stillbirths from the gestational age of $22+0$ weeks onward and/or birth weight of at least $500 \mathrm{~g}$. The register collects data on planned and unplanned home deliveries separately. This information is collected not until the infant is born. It includes diagnoses and treatments of infants by the age of seven days or at discharge. Information concerning Apgar scores at five minutes of age is not available for the period between October 1990 and December 2003. This partly explains why $66 \%$ of these scores were missing and because of that we analyzed only 1-minute Apgar scores. The data in the Medical Birth Register also include maternal and delivery characteristics and obstetric procedures. Causes of death were collected from the Cause of Death Register maintained by Statistics Finland. Travel distances between the delivery unit and home municipality were calculated by using a web-based route planner. We used the shortest distance between the home municipality and the nearest delivery unit according to the location of these units in 2015. Rural and urban municipalities were categorized according to Statistics Finland [26].

This national retrospective study included all planned home deliveries in Finland from 1996 to 2013. During these years 1,053,802 infants were born in Finland. Of these infants, 197 were born at home as planned and a total of $1,051,139$ infants were born at the hospital. We excluded unplanned out-of-hospital deliveries $(n=1420)$ and newborns with no information on the place of birth $(n=1046)$. We also reclassified seven cases which were clearly misclassified as planned home deliveries, having, for example, indications for elective cesarean section.

To compare perinatal and maternal mortality and morbidity reliably we excluded preterm births (length of gestation at birth less than $37+0$ weeks), deliveries with no information on gestational age, cesarean sections, vacuum extractions, forceps deliveries and deliveries without information about the mode of childbirth. After exclusions, there were 170 infants in the study group and 720,047 infants in the control group. In total, seven infants in the planned home delivery group were admitted to a neonatal care unit but only five of them were included in the study group and analysis, on the basis of the exclusion criteria mentioned above. One of the excluded infants was preterm and the other's gestational age at birth was not mentioned in the birth register.

Birth weight related to gestational age at birth was analyzed using Finnish growth curves [27]. Small for gestational age (SGA) means that weight at birth is two or more standard deviations (SD) below the population average. Large for gestational age (LGA) is a weight two or more SDs greater than the average. Socioeconomic status was defined by using the mother's occupation and was divided into four groups: upper-level and lower-level employees, manual workers and others. The group of "other" included students, housewives, and unclassifiable cases. Maternal age, parity, gestational age, birth weight, and Apgar scores were also divided into categories and analyzed both as dichotomous and categorized variables. Post-term pregnancy was defined as at length of gestation at birth of $42+$ 0 weeks or more. Congenital anomalies were divided into major and minor anomalies according to the classification of European surveillance of congenital anomalies [28]. We report only major congenital anomalies, since the reporting of minor anomalies varies by time and place.

For analysis of maternal morbidity, we included diagnoses of chorioamnionitis, retained placenta, placenta accreta, placenta previa, placental abruption, antepartum hemorrhage, hemorrhage during delivery, postpartum hemorrhage, perineal tears, uterine rupture, thromboembolism, and maternal sepsis or other puerperal infections. Maternal deaths were reported separately.

Current Finnish national guidelines for planned home delivery include the following: absence of any maternal preexisting disease, uncomplicated singleton pregnancy, at least one previous delivery, vertex presentation, no previous cesarean section or operative vaginal delivery, absence of group B streptococcus colonization, gestational weeks between $38+0$ and $41+6$ and two registered and certified midwives, or a midwife and a physician managing the labor [29]. Transfer time to the hospital should not be more than twenty minutes. We analyzed a subgroup of women who fulfilled the above-mentioned criteria that we could detect in the registers used.

\section{Statistical analyses}

To describe the data, medians, ranges and interquartile ranges were calculated for skew-distributed continuous variables and means and standard deviations for normally distributed variables. Frequencies and percentages were used for categorical variables. The infants born at home as planned and a control group were compared by using Mann-Whitney $U$ tests for skew-distributed continuous 


\section{Trends in planned home births 1996-2013}

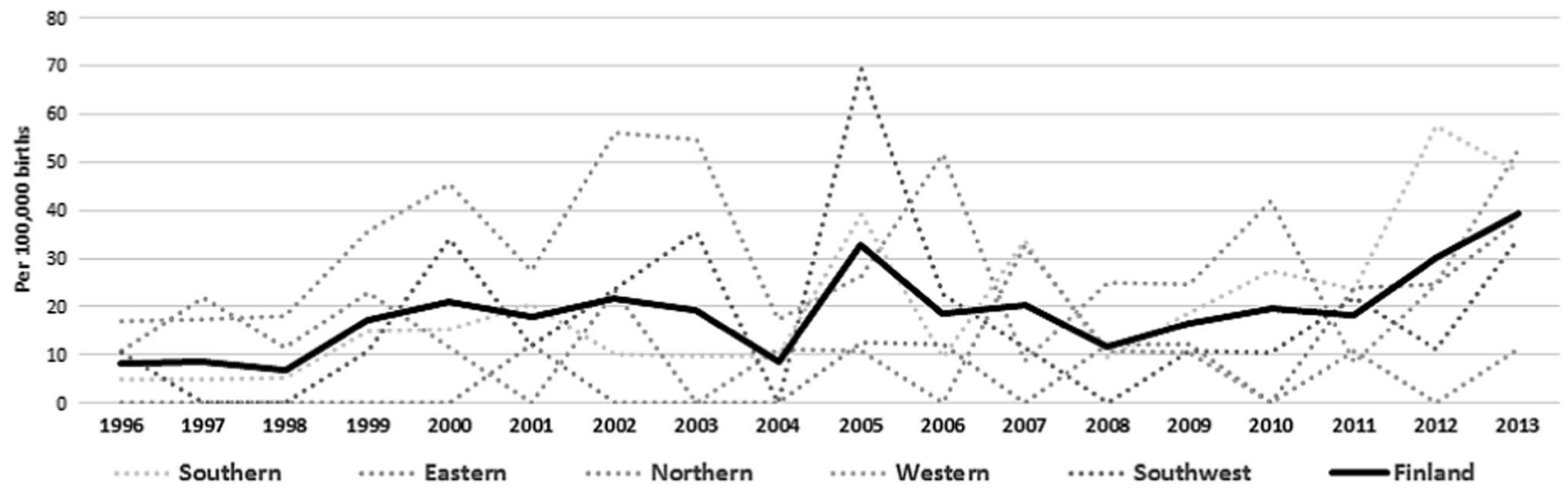

Fig. 1 Regional differences in trends of planned home deliveries in Finland (southern, eastern, northern, western, southwest, and the whole country)

variables, independent sample $t$-tests for normally distributed continuous variables, and chi-square tests or Fisher's exact tests for categorical variables, as appropriate. Logistic regression analyses were also performed, with results shown as odds ratios (ORs) with $95 \%$ confidence intervals (CIs). Values of $p<0.05$ were considered statistically significant. The analyses were carried out by using IBM SPSS Statistics for Windows, Version 22.0 software (IBM Corp., Armonk, NY). The Cochran Armitage trend test (StatXact version 4.0.1) was used in order to determine statistical significance of change of the planned home delivery rates during the study period.

\section{Results}

\section{Trends in rates of planned home deliveries}

During the study period, a total of 197 infants, on average 23.6 infants per 100,000 births were born at home as planned. Finland is divided into five specific catchment areas. Related to the number of deliveries, planned home births occurred most often in the western Finland area (37.6 per 100,000 births). According to the statistical grouping of municipalities, the home municipality was defined as rural in $124(63 \%)$ cases [26]. The rate of planned home deliveries rose almost fivefold from 8.3 (in 1996) to 39.4 (in 2013) per $100,000(p<0.001)$ but they are still very rare (Fig. 1).

\section{Maternal characteristics and outcomes}

Mothers who delivered at home as planned were older (mean 31.8 vs. 30.0 years, $p<0.001$ ), had better socioeconomic positions, smoked less often, had more previous deliveries, had fewer prenatal visits and shorter durations of labor (first and second phase). There were no differences in the rate of living in a partnership, in nationality or in distance from home to the delivery unit (Table 1). In 125 $(63 \%)$ cases pregnancies prior to planned home deliveries deviated from national recommendations, i.e. they were not low-risk pregnancies. A total of $25(12.7 \%)$ of the mothers were nulliparous. Four $(2.0 \%)$ mothers had gestational diabetes without the need of insulin treatment. One mother $(0.5 \%)$ had had a previous cesarean section and seven mothers $(3.6 \%)$ had a history of stillbirth. In the planned home delivery group there was one $(0.5 \%)$ twin delivery and one $(0.5 \%)$ fetus in breech position at the time of birth. The median length of gestation was longer and premature deliveries were statistically significantly less common in the planned home delivery group. Lengths of gestation at birth are given in Table 2.

No maternal deaths or adverse maternal outcomes were registered during the study period in the study group. Episiotomy was performed significantly less often in cases of planned home births; (2 (1.2\%) vs. 196,744 (27.3\%), $p<$ $0.001)$. No third- or fourth-degree perineal tears, need for blood transfusion postpartum, chorioamnionitis (infections of the amniotic sac and membranes), umbilical cord complications (prolapsed cord or other forms of compressions of the cord), or cases of placental abruption or labor dystocia were recorded in the study group. Unfortunately we could not identify the number or characteristics of those mothers who were transferred from home to hospital during labor, since registration is based on the actual place, not the intended place of birth.

\section{Infant characteristics and outcomes}

Infant outcomes and characteristics are listed in Tables 2, 3, 4 and 5. Most of the infants in the planned home delivery group were of a size appropriate for gestational age. Infants 
Table 1 Characteristics of parturients, pregnancies and deliveries

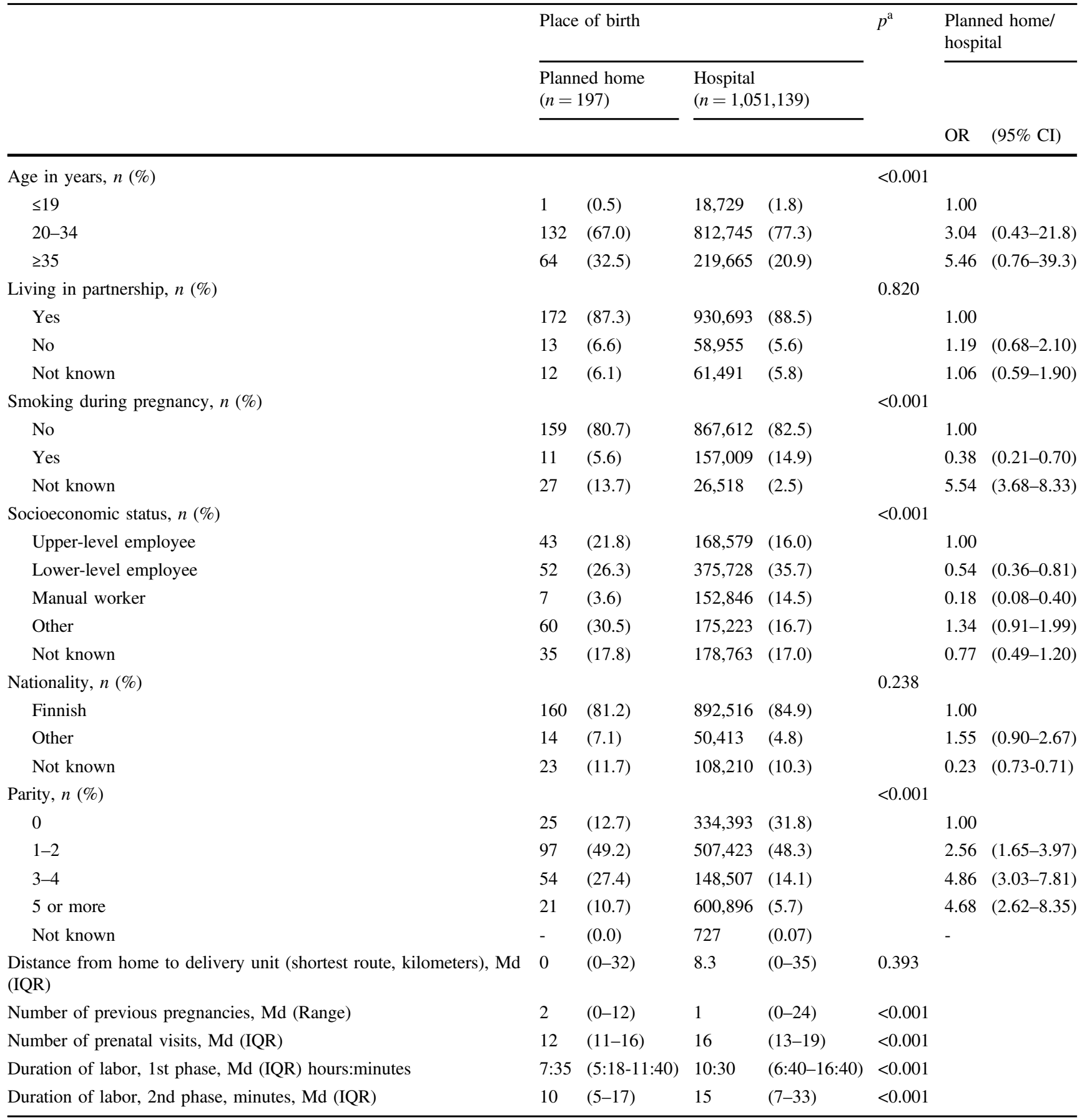

$O R$ odds ratio, $C I$ confidence interval, $M d$ median, $I Q R$ interquartile range

a'Differences between planned home deliveries and controls were assessed by using Pearson's Chi-Square test, Fisher's exact test, the MannWhitney $U$ test and the independent samples $t$-test, as appropriate

in the home delivery group were heavier (mean birth weight $3592 \mathrm{~g}$ vs. $3505 \mathrm{~g}, p=0.01$ ) and more frequently had oneminute Apgar scores less than 7. Congenital anomalies were rare within the study group. However, there were four infants with major congenital anomalies including diagnoses of patent ductus arteriosus (GA more than 37 weeks), a non-specified syndrome, trisomy 18 (Edwards syndrome), Klinefelter's syndrome and left heart hypoplasia syndrome. Infants in the study group suffered significantly fewer birth traumas. 
Table 2 Characteristics and outcomes of infants

\begin{tabular}{|c|c|c|c|c|c|c|c|}
\hline & \multicolumn{5}{|c|}{ Place of birth } & \multicolumn{2}{|c|}{$\begin{array}{l}\text { Planned home/ } \\
\text { hospital }\end{array}$} \\
\hline & \multicolumn{2}{|c|}{ Home $(n=197)$} & \multicolumn{2}{|c|}{ Hospital $(n=1,051,139)$} & $p^{\mathrm{a}}$ & & \\
\hline $\begin{array}{l}\text { Length of gestation at birth (weeks + days), median } \\
\text { (interquartile range) }\end{array}$ & $40+0$ & $\begin{array}{l}(38+5-40+ \\
5)\end{array}$ & $39+6$ & $\begin{array}{l}(38+6-40+ \\
5)\end{array}$ & 0.005 & & \\
\hline Length of gestation at birth, $n(\%)$ & & & & & $<0.001$ & & \\
\hline $37+0-42+0$ & 165 & $(83.8)$ & 938,498 & $(89.3)$ & & 1.00 & \\
\hline $22+0-31+6$ & - & $(0.0)$ & 9986 & $(1.0)$ & & - & \\
\hline $32+0-36+6$ & 1 & $(0.5)$ & 51,463 & (4.9) & & 0.11 & $(0.02-0.81)$ \\
\hline$>42+0$ & 3 & $(1.5)$ & 48,187 & (4.6) & & 0.61 & $(0.19-1.90)$ \\
\hline Not known & 28 & $(14.2)$ & 3005 & $(0.3)$ & & 54.1 & $(36.2-80.9)$ \\
\hline Birth weight $(\mathrm{g}), n(\%)$ & & & & & $<0.001$ & & \\
\hline 2500-3999 & 132 & $(67.0)$ & 816,893 & $(77.7)$ & & 1.00 & \\
\hline $4000-5500$ & 33 & $(16.8)$ & 187,353 & $(17.8)$ & & 1.09 & $(0.74-1.60)$ \\
\hline $1500-2499$ & 3 & $(1.5)$ & 37,190 & $(3.5)$ & & 0.50 & $(0.16-1.57)$ \\
\hline $500-1499$ & - & $(0.0)$ & 8990 & $(0.9)$ & & - & \\
\hline Not known & 29 & $(14.7)$ & 713 & $(0.1)$ & & 252 & $(167-379)$ \\
\hline Gestational age, $n(\%)$ & & & & & $<0.001$ & & \\
\hline Appropriate for GA & 163 & $(82.7)$ & 992,207 & $(94.4)$ & & 1.00 & \\
\hline Small for GA & 2 & $(1.0)$ & 25,246 & $(2.4)$ & & 0.48 & $(0.12-1.95)$ \\
\hline Large for GA & - & $(0.0)$ & 29,392 & $(2.8)$ & & - & \\
\hline Not known & 32 & $(16.2)$ & 4294 & $(0.4)$ & & 45.4 & $(31.0-66.3)$ \\
\hline
\end{tabular}

${ }^{a}$ Differences between planned home deliveries and controls were tested by using Pearson's Chi-Square test, Fisher's exact test or Mann Whitney $U$-test, as appropriate

Five infants (2.9\%) in the study group and 41,905 (5.8\%) infants born at hospital were admitted to a neonatal care unit after birth $(p=0.11)$.

In the study group there were two deaths, a couple of twins born at $37+4$ week's gestation. Twin A had a birth weight of $2390 \mathrm{~g}$. He did not need resuscitation, but he needed invasive ventilator therapy. He had a diagnosis of severe birth asphyxia and the official cause of death was hypoxic-ischemic encephalopathy. Twin B was stillborn and his cause of death remains unknown. No Apgar scores were mentioned in either case. Their mother was a 28 -yearold healthy woman living in the same city where the delivery unit was located. The known risk factors associated with the delivery were having a multiple pregnancy, and nulliparity. Overall, deaths were rare in both the study and control groups.

After the exclusion of mothers who did not meet the above-mentioned current national guideline criteria, there were 72 mothers who delivered at home as planned, and 219,062 controls. None of their infants died during the perinatal period. As regards other perinatal outcomes, infants who were born at home had higher risks of invasive ventilation and hypothermia (Table 4). However, a lower percentage of these infants had at least one of the adverse outcomes listed in Tables 3 and 4 compared with infants who were born at the hospital; 5 (6.9\%) vs. 30297 (13.8\%), although the difference was not statistically significant $(p=$ 0.09 ). There were no significant differences in mortality or morbidity between those infants whose mothers met the criteria for planned home deliveries and those whose mothers did not (Table 5).

\section{Discussion}

Each country has a maternity care system of its own and home deliveries are integrated into them in different ways. In Finland, we have a low perinatal mortality rate, approximately $0.4 \%$, which reflects a high-quality maternal health care system, and delivery and neonatal units. We have national guidelines for planned home deliveries, but hospital deliveries are nevertheless recommended in every case.

The American Academy of Pediatrics (AAP) [30] and the American College of Obstetricians and Gynecologists (ACOG) [31] have published criteria for planned home births and even stricter guidelines have been published in Finland [29]. The purpose of the recommendations is to prevent planned home deliveries in high-risk pregnancies. 
Table 3 Morbidity and mortality of infants; study cases and controls

\begin{tabular}{|c|c|c|c|c|c|c|c|}
\hline & \multicolumn{5}{|c|}{ Place of birth } & \multicolumn{2}{|c|}{ Planned home } \\
\hline & \multicolumn{2}{|c|}{$\begin{array}{l}\text { Planned home } \\
(n=170)\end{array}$} & \multicolumn{2}{|c|}{$\begin{array}{l}\text { Hospital } \\
(n=720,047)\end{array}$} & \multirow[t]{2}{*}{$p^{\mathrm{a}}$} & & \\
\hline & $n$ & $(\%)$ & $n$ & $(\%)$ & & OR & $(95 \% \mathrm{CI})$ \\
\hline One-minute Apgar scores & & & & & $<0.001$ & & \\
\hline $7-10$ & 148 & $(87.1)$ & 696,968 & $(96.8)$ & & 1.00 & \\
\hline $0-6$ & 8 & $(4.7)$ & 21,891 & $(3.0)$ & & 1.72 & $(0.84-3.51)$ \\
\hline Missing & 14 & $(8.2)$ & 1188 & $(0.2)$ & & 56 & $(32-96)$ \\
\hline Resuscitation $^{\mathrm{b}}$ & - & $(0.0)$ & 1729 & $(0.2)$ & 1.00 & - & \\
\hline Asphyxia at birth & 2 & $(1.2)$ & 5339 & $(0.7)$ & 0.36 & 1.59 & $(0.39-6.43)$ \\
\hline Birth trauma & - & $(0.0)$ & 16,816 & $(2.3)$ & 0.04 & - & \\
\hline Meconium aspiration & - & $(0.0)$ & 858 & $(0.1)$ & 1.00 & - & \\
\hline Respiratory distress ${ }^{\mathrm{b}}$ & - & $(0.0)$ & 8710 & $(2.2)$ & 0.28 & - & \\
\hline Pulmonary hypertension ${ }^{\mathrm{b}}$ & - & $(0.0)$ & 269 & $(0.04)$ & 1.00 & - & \\
\hline Antibiotic treatment ${ }^{\mathrm{b}}$ & 4 & $(2.4)$ & 20,542 & (2.9) & 1.00 & 0.82 & $(0.30-2.21)$ \\
\hline Invasive ventilation $^{\mathrm{b}}$ & 2 & $(1.2)$ & 2021 & $(0.3)$ & 0.08 & 4.23 & $(1.05-17.1)$ \\
\hline Hypothermia $^{\mathrm{b}}$ & 1 & $(0.6)$ & 256 & $(0.04)$ & 0.06 & 16.6 & $(2.32-119)$ \\
\hline Congenital malformation & 7 & $(4.1)$ & 52,399 & (7.3) & 0.11 & 0.55 & $(0.26-1.17)$ \\
\hline Perinatal mortality & 2 & $(1.2)$ & 1102 & $(0.2)$ & 0.03 & 7.77 & $(1.92-31.4)$ \\
\hline
\end{tabular}

(Preterm births, operative deliveries and cases without information of possible prematurity or mode/place of birth were excluded)

$O R$ odds ratio, $C I$ confidence interval

a Differences between planned home deliveries and controls were tested by using Pearson's Chi-Square test, Fisher's exact test or the Mann Whitney $U$-test, as appropriate

${ }^{\mathrm{b}}$ Before the age of seven days
Our first finding was, that planned home deliveries are relatively rare in Finland $(0.02 \%)$ compared, for example, with the Netherlands (20\%), where planned home deliveries have traditionally been common [7]. This reflects the common attitude in favor of hospital deliveries in our country. Our results show, however, a rising trend in the occurrence of planned home deliveries. Some regional differences were also found.

Planned home delivery rates are also increasing in other developed countries, especially in the United States $[32,33]$. On the other hand, the home-birth rate has decreased in the Netherlands during the last two to three decades $[32,33]$. Women choosing a planned home delivery may feel dissatisfaction with a previous hospital delivery. They may wish to avoid delivery interventions and feel that home is the safest option, with a peaceful environment $[34,35]$. Regional differences in the planned OHD rates exist in spite of the fact that the guidelines for planned home deliveries are the same in whole Finland.

Our second finding was that the majority of women who plan to deliver at home do so regardless of the national recommendations. In our population this was associated to two perinatal deaths. This highlights the importance of the safety recommendations and calls for the responsibility of the healthcare professionals, who assist planned deliveries at home.
Our third finding was that even in those home deliveries that fulfilled the criteria of low-risk pregnancy and delivery, untoward neonatal outcomes, including hypothermia, asphyxia, and need of invasive ventilation, were overrepresented. In addition, although by a chance, our study group included infants with major congenital malformations. Thus, it is impossible to predict the course of delivery even in cases of low-risk labor. Rare but serious complications are not totally avoidable. The central issue of planned home delivery is the limited possibility to intervene when necessary. Continuous monitoring of fetal heart rate and contractions is unlikely to be available at home. Neonatal and also maternal complications can occur unexpectedly and may require immediate emergency cesarean section or other forms of intervention, and/or effective resuscitation of the infant. In these cases delay because of home delivery is always too long. These facts should be included in the counseling of pregnant women.

From the maternal point of view planned home deliveries may appear to be relatively safe, with some benefits compared with hospital deliveries. The lower rate of episiotomies can be partly explained by maternal characteristics such as the fact that most women were multiparous, the duration of labor was shorter, and there were no LGA infants in the group of planned home deliveries. 
Table 4 Morbidity and mortality of infants meeting the criteria for planned home birth. Infants who were born at home as planned and control infants born in the hospital

\begin{tabular}{|c|c|c|c|c|c|c|c|}
\hline & \multicolumn{4}{|c|}{ Place of birth } & \multirow[t]{3}{*}{$p^{\mathrm{a}}$} & \multicolumn{2}{|c|}{ Planned home } \\
\hline & \multicolumn{2}{|c|}{$\begin{array}{l}\text { Planned } \\
\text { home } \\
(\mathrm{n}=72)\end{array}$} & \multicolumn{2}{|c|}{$\begin{array}{l}\text { Hospital } \\
(\mathrm{n}=219,062)\end{array}$} & & & \\
\hline & $n$ & $(\%)$ & $n$ & $(\%)$ & & OR & $(95 \% \mathrm{CI})$ \\
\hline \multicolumn{3}{|l|}{ One-minute Apgar scores } & & & $<0.001$ & & \\
\hline $7-10$ & 66 & $(91.7)$ & 213,910 & $(97.6)$ & & 1.00 & \\
\hline $0-6$ & 2 & $(2.8)$ & 4844 & $(2.2)$ & & 1.34 & $(0.33-5.47)$ \\
\hline Missing & 4 & $(5.6)$ & 308 & $(0.1)$ & & 42.1 & $(15.3-116.2)$ \\
\hline Resuscitation $^{\mathrm{b}}$ & - & $(0.0)$ & 372 & $(0.2)$ & 1.00 & - & \\
\hline Asphyxia at birth & 1 & $(1.4)$ & 1027 & $(0.5)$ & 0.29 & 3.00 & $(0.42-21.5)$ \\
\hline Birth trauma & - & $(0.0)$ & 4913 & $(2.2)$ & 0.42 & - & \\
\hline Meconium aspiration & - & $(0.0)$ & 217 & $(0.1)$ & 1.00 & - & \\
\hline Respiratory distress ${ }^{\mathrm{b}}$ & - & $(0.0)$ & 2055 & $(0.9)$ & 1.00 & - & \\
\hline Pulmonary hypertension ${ }^{\mathrm{b}}$ & - & $(0.0)$ & 65 & $(<0.1)$ & 1.00 & - & \\
\hline Antibiotic treatment ${ }^{\mathrm{b}}$ & 2 & $(2.8)$ & 4765 & $(2.2)$ & 0.67 & 1.29 & $(0.32-5.24)$ \\
\hline Invasive ventilation $^{\mathrm{b}}$ & 1 & $(1.4)$ & 417 & $(0.2)$ & 0.13 & 7.34 & $(1.02-53.3)$ \\
\hline Hypothermia $^{\mathrm{b}}$ & 1 & $(1.4)$ & 66 & $(<0.1)$ & 0.02 & 46.7 & $(6.40-345)$ \\
\hline Congenital malformation & 2 & $(2.8)$ & 15,119 & $(6.9)$ & 0.24 & 0.39 & $(0.10-1.57)$ \\
\hline Perinatal mortality & - & $(0.0)$ & 233 & $(0.1)$ & 1.00 & - & \\
\hline
\end{tabular}

(Preterm births, operative deliveries and cases without information of possible prematurity or mode/place of birth were excluded)

Difference in this table compared to Table 3 is that only the cases that met the criteria for planned home birth were included into the study group

$O R$ odds ratio, $C I$ confidence interval

${ }^{a}$ Differences between planned home deliveries and controls were tested by using Pearson's Chi-Square test, Fisher's exact test or the Mann-Whitney $U$-test, as appropriate

${ }^{\mathrm{b}}$ Before the age of seven days
However, it is also possible that episiotomy may be favored in a hospital setting, since the episiotomy rate among multiparas varied from 15 to $5 \%$ during the study period in Finland [36], while in the study group it was only $1.2 \%$. Our findings of fewer episiotomies and no increase in maternal morbidity are consistent with the results of other studies [37].

Furthermore, no emergency obstetric complications such as placental abruption, uterine rupture or retained placenta were registered in the study group, even though multiparity is a risk factor of these conditions. Likewise, the need for blood transfusion was not increased in the study group, reflecting no severe postpartum hemorrhage complications. However, these severe complications are rare-for example, the incidence of placental abruption has been reported to be $0.4 / 1000$ deliveries in Finland [38] and our limited amount of material does not allow us to estimate the risks of these rare but life-threatening complications in a homedelivery setting. Furthermore, there were no serious maternal infections in the planned home-delivery group. This could be a result of the shorter duration of labor and fewer invasive procedures such as episiotomies. A home setting does also not particularly expose a woman to infections.

It is, however, very likely that all the above-mentioned complications are underreported in planned home delivery cases, because complicated cases require a transfer and treatment in hospital.

Although Finnish pediatricians and obstetricians do not support home birth, it is important to find out how to promote physiological birth where appropriate. Interventions during labor should be driven by clinical need. Increasing popularity of planned home deliveries challenges the staff working in delivery units to re-evaluate which routine procedures are necessary for safety in labor.

The greatest limitation of our study is that we had no data on the intended place of birth before the delivery. This may lead to underestimation of perinatal mortality and morbidity, because transfers to the hospital during delivery are classified in Finland as hospital births or as transfer births. Previous studies have shown that neonatal mortality and morbidity are increased if there has been a transfer to the hospital during labor [9]. The Medical Birth Register would be improved by collecting information on the intended 
Table 5 Morbidity and mortality of infants whose mothers met the criteria for low-risk pregnancy and delivery with infants whose mothers had risk factors for planned home delivery

\begin{tabular}{|c|c|c|c|c|c|c|c|}
\hline & \multicolumn{2}{|c|}{$\begin{array}{l}\text { Planned home } \\
\text { births-low risk } \\
\text { group }(\mathrm{n}=72)\end{array}$} & \multicolumn{2}{|c|}{$\begin{array}{l}\text { Planned home } \\
\text { births with } \\
\text { risk factors } \\
(\mathrm{n}=98)\end{array}$} & \multirow[t]{2}{*}{$p^{\mathrm{a}}$} & \multicolumn{2}{|c|}{$\begin{array}{l}\text { No risk factors vs. } \\
\text { risk factors }\end{array}$} \\
\hline & $n$ & $(\%)$ & $n$ & $(\%)$ & & OR & $(95 \% \mathrm{CI})$ \\
\hline One-minute Apgar scores & & & & & 0.332 & & \\
\hline $7-10$ & 66 & $(91.7)$ & 82 & $(83.7)$ & & 1.00 & \\
\hline $0-6$ & 2 & $(2.8)$ & 6 & $(6.1)$ & & 0.41 & $(0.08-2.12)$ \\
\hline Missing & 4 & $(5.6)$ & 10 & $(10.2)$ & & 0.50 & $(0.15-1.66)$ \\
\hline Resuscitation $^{\mathrm{b}}$ & - & $(0.0)$ & - & $(0.0)$ & - & - & \\
\hline Asphyxia at birth & 1 & $(1.4)$ & 1 & $(1.0)$ & 1.000 & 1.37 & $(0.08-22.2)$ \\
\hline Birth trauma & - & $(0.0)$ & - & $(0.0)$ & - & - & \\
\hline Meconium aspiration & - & $(0.0)$ & - & $(0.0)$ & - & - & \\
\hline Respiratory distress $^{\mathrm{b}}$ & - & $(0.0)$ & - & $(0.0)$ & - & - & \\
\hline Pulmonary hypertension ${ }^{\mathrm{b}}$ & - & $(0.0)$ & - & $(0.0)$ & - & - & \\
\hline Antibiotic treatment ${ }^{\mathrm{b}}$ & 2 & $(2.8)$ & 2 & $(2.0)$ & 1.000 & 1.37 & $(0.19-9.97)$ \\
\hline Invasive ventilation $^{\mathrm{b}}$ & 1 & $(1.4)$ & 1 & $(1.0)$ & 1.000 & 1.37 & $(0.08-22.2)$ \\
\hline Hypothermia $^{\text {b }}$ & 1 & $(1.4)$ & - & $(0.0)$ & 0.424 & - & \\
\hline Congenital malformation & 2 & $(2.8)$ & 5 & $(5.1)$ & 0.700 & 0.53 & $(0.10-2.82)$ \\
\hline Perinatal mortality & - & $(0.0)$ & 2 & $(2.0)$ & 0.509 & - & \\
\hline
\end{tabular}

(Preterm births, operative deliveries and cases without information of possible prematurity or mode/place of birth were excluded)

Odds ratios (OR) with $95 \%$ confidence intervals (CI)

a'Differences between groups were tested by Pearson's Chi-Square / Fisher's exact test/ Mann-Whitney U-test

${ }^{b}$ Before the age of seven days place of birth at the onset of labor. In addition, the professions of health care workers attending home deliveries should be registered.

Another limitation is the substantial proportion of missing data concerning home deliveries. Midwives taking care of home deliveries should send the data to the Medical Birth Registry, but these data are often less complete than for hospital births. Additionally, our planned home delivery group was limited by a small sample size and absolute figures in some outcomes remained small, but on the other hand we had a long study period covering all births and stillbirths in Finland in an 18-year study period.

\section{Conclusions}

Planned home deliveries are relatively rare in Finland but their number increased during the study period.

Planned home deliveries seemed to have some advantages to the mother compared with hospital deliveries, such as fewer episiotomies and shorter duration of labor. As regards the infants, planned home deliveries were associated with lower Apgar scores but fewer cases of birth trauma. It is notable that infant deaths in the planned home delivery group occurred to the ones whose mother did not fulfill the national criteria for planned home deliveries. Even in lowrisk home deliveries, the occurrence of asphyxia, hypothermia, and need of assisted ventilation appeared to be increased, although the absolute number of them was low. Such facts should be included in the counseling of pregnant women, who are aiming to deliver at home. It is also important to develop the hospital environment and seek ways to promote physiological birth where appropriate in delivery units.

Acknowledgements This manuscript is funded by Pirkanmaa Hospital District, Scientific Foundation of the City of Tampere and Foundation for Pediatric Research.

\section{Compliance with ethical standards}

Conflict of interest The authors declare that they have no conflict of interest.

\section{References}

1. Snowden JM, Tilden EL, Snyder J, Quigley B, Caughey AB, Cheng YW. Planned out-of-hospital birth and birth outcomes. N Engl J Med. 2015;373:2642-53.

2. Grünebaum A, McCullough LB, Sapra KJ, Brent RL, Levene MI, Arabin B, et al. Early and total neonatal mortality in relation to 
birth setting in the United States, 2006-2009. Am J Obstet Gynecol. 2014;211:390. e1-7

3. Grünebaum A, McCullough LB, Sapra KJ, Arabin B, Chervenak FA. Planned home births: the need for additional contraindications. Am J Obstet Gynecol. 2017;216:401. e1-8

4. Malloy MH. Infant outcomes of certified nurse midwife attended home births: United States 2000 to 2004. J Perinatol. 2010;30:622-7.

5. Bastian H, Keirse MJ, Lancaster PA. Perinatal death associated with planned home birth in Australia: population based study. BMJ. 1998;317:384-8.

6. Hutton EK, Cappelletti A, Reitsma AH, Simioni J, Horne J, McGregor C, et al. Outcomes associated with planned place of birth among women with low-risk pregnancies. CMAJ. 2016;188:e80-90.

7. de Jonge A, Geerts CC, van der Goes BY, Mol BW, Buitendijk SE, Nijhuis JG. Perinatal mortality and morbidity up to 28 days after birth among 743070 low-risk planned home and hospital births: a cohort study based on three merged national perinatal databases. BJOG. 2015;122:720-8.

8. Gaudineau A, Sauleau EA, Nisand I, Langer B. Obstetric and neonatal outcomes in a home-like birthcentre: a case-control study. Arch Gynecol Obstet. 2013;287:211-6.

9. Kennare RM, Keirse MJ, Tucker GR, Chan AC. Planned home and hospital births in South Australia, 1991-2006: differences in outcomes. Med J Aust. 2010;192:76-80.

10. Hutton EK, Reitsma AH, Kaufman K. Outcomes associated with planned home and planned hospital births in low-risk women attended by midwives in Ontario, Canada, 2003-2006: A Retrospective Cohort Study. Birth. 2009;36:180-9.

11. van der Kooy J, Poeran J, de Graaf JP, Birnie E, Denktas S, Steegers EA, et al. Planned home compared with planned hospital births in the Netherlands: intrapartum and early neonatal death in low-risk pregnancies. Obstet Gynecol. 2011;118:1037-46.

12. Lindgren HE, Rådestad IJ, Christensson K, Hildingsson IM. Outcome of planned home births compared to hospital births in Sweden between 1992 and 2004. A population-based register study. Acta Obstet Gynecol Scand. 2008;87:751-9.

13. de Jonge A, van der Goes BY, Ravelli AL, Amelink-Verburg MP, Mol BW, Nijhuis JG, et al. Perinatal mortality and morbidity in a nationwide cohort of 529688 low-risk planned home and hospital births. BJOG. 2009;116:1177-84.

14. Li Y, Townend J, Rowe R, Brocklehurst P, Knight M, Linsell L, et al. Perinatal and maternal outcomes in planned home and obstetric unit births in women at higher risk of complications: secondary analysis of the Birthplace national prospective cohort study. BJOG. 2015;122:741-3.

15. Cheng YW, Snowden JM, King TL, Caughey AB. Selected perinatal outcomes associated with planned home births in the United States. Am J Obstet Gynecol. 2013;209:325. e1-8

16. Wax JR, Pinette MG, Cartin A, Blackstone J. Maternal and newborn morbidity by birth facility among selected United States 2006 low-risk births. Am J Obstet Gynecol. 2010;202:152. e1-5

17. Halfdansdottir B, Smarason AK, Olafsdottir OA, Hildingsson I, Sveinsdottir H. Outcome of planned home and hospital births among low-risk women in Iceland in 2005-2009: A retrospective cohort study. Birth. 2015;42:16-26.

18. Janssen PA, Saxell L, Page LA, Klein MC, Liston RM, Lee SK. Outcomes of planned home birth with registered midwife versus planned hospital birth with midwife or physician. CMAJ. 2009;181:377-83.
19. Davis D, Baddock S, Pairman S, Hunter M, Benn C, Wilson D, et al. Planned place of birth in New Zealand: does it affect mode of birth and intervention rates among low-risk women? Birth. 2011;38:111-9.

20. Grünebaum A, McCullough LB, Sapra KJ, Brent RL, Levene MI, Arabin B, et al. Apgar score of 0 at $5 \mathrm{~min}$ and neonatal seizures or serious neurologic dysfunction in relation to birth setting. Am J Obstet Gynecol. 2013;209:323. e1-6

21. Declercq E, Macdorman MF, Menacker F, Stotland N. Characteristics of planned and unplanned homebirths in 19 states. Obstet Gynecol. 2010;116:93-9.

22. Danilack VA, Nunes AP, Phipps MG. Unexpected complications of low-risk pregnancies in the United States. Am J Obstet Gynecol. 2015;212:809. e1-6

23. Grünebaum A, McCullough LB, Brent RL, Arabin B, Levene MI, Chervenak FA. Perinatal risks of planned home births in the United States. Am J Obstet Gynecol. 2015;212:350. e1-6

24. Blix E, Kumle M, Kjærgaard H, Øian P, Lindgren HE. Transfer to hospital in planned home births: a systematic review. BMC Pregnancy Childbirth. 2014;14:179.

25. Blix E, Kumle MH, Ingversen K, Huitfeldt AS, Hegaard HK, Ólafsdóttir ÓÁ, et al. Transfers to hospital in planned home birth in four Nordic countries - a prospective cohort study. Acta Obstet Gynecol Scand. 2016;95:420-8.

26. Statistical grouping of municipalities. Official Statistics of Finland 2014.

27. Pihkala J, Hakala T, Voutilainen P, Raivio K. Characteristic of recent fetal growth curves in Finland (in Finnish). Duodecim. 1989;105:1540-6.

28. European surveillance of congenital anomalies. EUROCAT Guide 1.4 Section 3.2. 2014.

29. Klemetti R, Hakulinen-Viitanen T. National guidelines for maternity healthcare (in Finnish). Finland: National Institute for Health and Welfare; 2013.

30. American Academy of Pediatrics. Policy statement on planned home birth. Pediatrics. 2013;131:1016-20.

31. American College of Obstetricians and Gynecologists. Planned home birth. Committee Opinion No. 669. Obstet Gynecol. 2016;128:e26-31.

32. Chervenak FA, McCullough LB, Brent RL, Levene MI, Arabin B. Planned home birth: the professional responsibility response. Am J Obstet Gynecol. 2013;208:31-8.

33. MacDorman MF, Declercq E. Trends and Characteristics of United States Out- of- Hospital Births 2004-2014: New Information on Risk Status and Access to Care. Birth. 2016;43:116-24.

34. Bernhard C, Zielinsky R, Ackerson K, English J. Home birth after hospital birth: women's choices and reflections. J Midwifery Health. 2014;59:160-6.

35. Boucher D, Bennett C, McFarlin B, Freeze R. Staying home to give birth: why women in the United States choose home birth. J Midwifery Women's Health. 2009;54:119-26.

36. Parturients, delivers and newborn. National Institute for Health and Welfare, Finland 2016.

37. Wax JR, Pinette MG, Cartin A. Home versus Hospital Birth process and outcome. Obstet Gynecol Surv. 2010;65:132-40.

38. Tikkanen M, Riihimäki O, Gissler M, Luukkaala T, Metsäranta $\mathrm{M}$, Andersson S, et al. Decreasing incidence of placental abruption in Finland during 1980-2005. Acta Obstet Gynecol Scand. 2012;91:1046-52. 